\title{
Uso de drogas ilícitas na prática do homicídio
}

\author{
The use of illicit drugs in the practice of homicide
}

Uso de drogas ilícitas en la práctica del homicidio

Clarysse do Carmo Lima ${ }^{1}$

Renan Pereira de Lima² Arlandia Cristina Lima Nobre ${ }^{3}$

RESUMO: Introdução - O impacto da violência no desenvolvimento urbano tem merecido destaque. As consequências da exposição à violência mais especificamente aos homicídios e ao uso de drogas incluem alterações fisiológicas, neurológicas e de âmbito interpessoal. Objetivo - Este estudo teve como objetivo verificar a prevalência de exposição à violência comunitária e identificar associações com exposição às drogas ilícitas e envolvimento com o crime. Métodos - Trata-se de um estudo retrospectivo, com uma abordagem observacional e descritiva, a partir da análise de prontuários de condenados pela prática do homicídio, buscando tipificação do crime e informações sobre o uso de drogas ilícitas. Resultados - Dos 40 presos em fase de execução cujos prontuários foram analisados, todos eram do sexo masculino, com predomínio da faixa etária entre 21 a 40 anos ( $n=30,75 \%$ ). No que concerne ao grau de escolaridade $47,5 \%$ ( $n=19)$ não concluíram o ensino fundamental, 35,0\% $(n=14)$ eram analfabetos e $17,5 \%$ $(n=7)$ apresentavam o ensino médio completo. Considerando a tipificação do crime observou-se que todos cometeram o homicídio na modalidade qualificada, quanto ao motivo, pela futilidade conforme disposto no artigo 121. Conclusão - Ao consumir algum tipo de droga ilícita o indivíduo, perde o controle emocional tendo diversos sintomas como alucinação, euforia e psicose que poderiam servir de motivação para a prática de delitos com requintes de crueldade.

Palavras chaves: Drogas ilícitas. Homicídio. Esquizofrenia. Crime.

ABSTRACT: Introduction - The impact of violence on urban development has been an important subject of attention lately. The consequences of the exposure to violence, such as homicides and drug consumption, in particular, result in physiological, neurological and interpersonal alterations. Objective - This study has the objective of verifying the relation between the exposure to community violence and the use of illegal drugs and engagement in criminal activities. Methods - This is a retrospective study with an observational and descriptive approach. It was conducted by analyzing the medical records of prisoners who were convicted of murder andtypifying the crime and information about the use of illegal drugs. Results - Out of 40 convicted prisoners whose medical records where analyzed, $100 \%$ were male with the prevalence of the 21 to 40 years-old age group $(n=30,75 \%)$. As for their schooling, 47.5\% $(n=19)$ did not finish elementary school, 35\% $(n=14)$ were illiterate and $17.5 \%(n=7)$ finished high school. Filtering the data by th type of

\footnotetext{
${ }^{1}$ Farmacêutica, Fortaleza, Ceará. E-mail: claryssefarma@hotmail.com

2 Graduando em Farmácia, Universidade de Fortaleza. E-mail: renan1647@edu.unifor.br

${ }^{3}$ Farmacêutica, doutora em farmacologia, Advogada, Professora titular, Curso de farmácia, Universidade de Fortaleza. Email: arlandia@unifor.br
} 
crime, it was observed that all prisoners have been convicted of murder, based on futile motivations, as described in article 121. Conclusion - Under the influence of illegal drugs people tend to lose their emotional control and display symptoms like: hallucinations, euphoria, psychosis, among others, which could be a motivation to the practice of crimes with exquisite cruelty.

Keywords: Street Drugs. Homicide. Schizophrenia. Crime.

RESUMEN: Introducción: El impacto de la violencia en el desarrollo urbano tiene ganado relieve. Las consecuencias de la exposición a la violencia, en particular los homicidios y al uso de drogas, incluyen alteraciones fisiológicas, neurológicas y de ámbito interpersonal. Objetivo: Este estudio tuvo como objetivo verificar la prevalencia de la exposición a la violencia comunitaria e identificar las asociaciones en exposición a drogas ilicitas y relación con el crimen. Métodos: Este estudio es retrospectivo, con un abordaje observacional y descriptivo. El tiene como basis el a análisis de los registros médicos de condenados por la práctica de homicidio, a buscar tipificación del crimen e informaciones sobre el uso de drogas ilícitas. Resultados: De 40 presos condenados y cuyos registros médicos fueron analizados, todos eran del sexo masculino, con predomináncia de la faja etária entre 21 a 40 años $(n=30,75 \%)$. En lo que concierne al nivel de escolaridad $47,5 \% \quad(n=19)$ no concluyeron la enseñanza básica, 35,0\% $(n=14)$ eran analfabetos, $17,5 \% \quad(n=7)$ presentaban la enseñanza media completa. A considerar la tipificación del crimen, fue observado que todos han cometido el homicidio en la modalidad cualificada. Con respecto a la motivación, los crímenes son considerados fútiles en acuerdo al dispuesto en el artículo 121. Conclusión: Al consumir algún tipo de droga ilícita, el sujeto pierde el control emocional teniendo diversos síntomas como alucinación, euforia, psicosis, ilusiones, síntomas de esquizofrenia, y otros, que podrían servir de motivación para la práctica de delitos con requintes de crueldad.

Palabras-Ilave: Drogas Ilícitas, Homicidio, Esquizofrenia, Crimen

\section{Introdução}

O processo de urbanização no Brasil foi acompanhado pela elevação sensível das taxas de criminalidade e os homicídios vêm afetando de maneira cada vez mais acentuado o cotidiano das regiões metropolitanas brasileiras. Destaca-se que, entre 2005 a 2015, o número de homicídios no Brasil passou de 48.136 casos para 59.080 , sendo que no estado do Ceará foi observado aumento de 1.699 casos para 4.163 casos (2),(5),(6),(14).

O homicídio tem sido apontado como a principal causa da elevação das taxas de mortalidade por violência no Brasil e no mundo. Em 2015, com a taxa de 28,9 homicídios por 100.000 habitantes diários, o que equivale a 1,4 massacres do Carandiru a cada dia. Estudo realizado pelo Sistema de Informações de Mortalidade (SIM) em 2015 a cidade de Maracanaú no estado do Ceará ocupou a 6ª posição no ranking dos 30 municípios mais violentos com população superior a 100 mil habitantes com 172 casos e a cidade de 
Fortaleza ocupou a 13ª posição com 1.729 casos, sendo que no estado do Ceará as taxas de homicídio por 100.000 habitantes tiveram crescimento de 145\% de 2005 a 2015 (7).

O termo Homicídio é a violenta coedes ab homini injuste patrata, ou seja, o homicídio é a violenta ocisão de um homem injustamente praticada por outro, sendo definido pelo doutrinador Cezar Roberto Bitencout (17).

Homicídio como nomen iuris do crime que suprime a vida alheia, independente das condições ou circunstâncias em que esse crime é praticado. Distinguiu, no entanto, três modalidades: homicídio simples (art. 121, caput), homicídio privilegiado (art. $121 \S 1^{\circ}$ ) e homicídio qualificado (art. $121 \S 2^{\circ}$ ). O atual Código preferiu não criar figuras especiais, tais como parricídio, matricídio ou fratricídio, rejeitando, enfim, a longa catalogação que o código anterior prescrevia (art. 294, $\S 1^{\circ}$, do CP de 1890). As circunstâncias e peculiaridades concretas é que deverão determinar a gravidade do fato e sua adequada tipificação em uma das três modalidades de homicídio que disciplina - simples, privilegiado ou qualificado.

De acordo com o Código Penal Brasileiro o homicídio pode ser simples ou qualificado previsto no artigo 121, caput, $\S 1^{\circ}$ e $\S 2^{\circ}$ e incisos I, II, III, IV, V respectivamente, onde no $\S$ $1^{\circ}$ o agente comete o crime impelido por motivo de relevante valor social ou moral, ou sob o domínio de violenta emoção, logo em seguida a injusta provocação da vítima, onde o juiz pode reduzir a pena de um sexto a um terço, quando for realizar a dosimetria da pena, e no $\S 2^{\circ}$ o homicídio será qualificado. No inciso I, o crime é praticado mediante paga ou promessa de recompensa, ou qualquer outro motivo torpe; no inciso II, praticado por motivo fútil; no inciso III será o homicídio praticado por meio de veneno, asfixia ou outro motivo insidioso ou cruel; no inciso IV é quando o homicídio é cometido à traição ou quando não há defesa do ofendido e, por fim, o inciso $V$ para assegurar a execução, a ocultação, a impunidade ou vantagem de outro crime (8).

O consumo de drogas tem sido reconhecido como um dos principais fatores, de riscos para as mortes por homicídios. Existem várias maneiras pelas quais os crimes podem estar associados a drogas, sendo a primeira delas os efeitos das substâncias tóxicas no comportamento das pessoas, e ainda o fato das drogas serem comercializadas ilegalmente fazendo com que as pessoas busquem cada vez mais recurso para manterem o vício (7).

Sendo o uso de drogas um problema de saúde pública, e consequentemente 
relacionado com aumento da violência e a prática do homicídio, é necessário que sejam feitos estudos para avaliar de que forma as substâncias químicas podem alterar 0 comportamento do indivíduo no âmbito social, ao ponto de levá-lo a cometer delitos.

Dessa forma, o estudo objetivou verificar a prevalência de exposição à violência comunitária e identificar associações com exposição às drogas ilícitas e envolvimento com o crime, buscando correlacionar com o uso de drogas ilícitas e a prática delituosa realizado no ano de 2012.

\section{Metodologia}

Trata-se de um estudo retrospectivo, com uma abordagem observacional e descritiva, a partir da análise de prontuários de condenados pela prática do homicídio, buscando tipificação do crime e informações sobre o uso de drogas ilícitas, realizado no período de agosto a outubro de 2012, no Hospital e Sanatório Penal Professor Otávio Lobo em Itaitinga, Fortaleza, Ceará, Brasil.

Foram analisados 40 prontuários, todos do sexo masculino. Excluíram-se aqueles que embora fossem usuários de drogas não cometeram homicídio. Coletou-se dados demográficos e, referentes a utilização de drogas e tipificação do crime.

Os dados foram analisados com o software Epi info 3.5.4, arquivados em um banco de dados eletrônico no Microsoft Excel e os resultados expressos em frequência absoluta, relativa e intervalos de confiança de $95 \%$. Os resultados dessas análises foram organizados em tabelas e/ou gráficos.

A pesquisa faz parte do projeto Panorama da Assistência Farmacêutica no Estado do Ceará aprovado pelo Comitê de Ética sob protocolo nํ258/2011.

\section{Resultados}

Quanto ao perfil demográfico dos 40 presos em fase de execução cujos prontuários foram analisados, todos eram do sexo masculino, com predomínio da faixa etária entre 21 a 40 anos $(n=30,75 \%)$. No que concerne ao grau de escolaridade $47,5 \%(n=19)$ não concluíram o ensino fundamental, 35,0\% ( $n=14)$ eram analfabetos e $17,5 \% \quad(n=7)$ apresentavam o ensino médio completo. Da amostra inclusa, 55\% $(n=22)$ eram usuários de drogas ilícitas e 45\% ( $n=18)$ não usuários (Tabela 1). 
O tempo médio de uso de drogas ilícitas, variou entre 6 a 10 anos e, observou-se ainda, que $15,0 \%$ eram reincidentes, não só pela prática do homicídio, mas também pelo cometimento de outros crimes, como, roubo, tipificado no artigo 157, e lesão corporal, artigo 129, ambos no Código Penal Brasileiro. Quanto ao uso da droga ao praticar o crime observou-se que $57,5 \%$ não fizeram uso das mesmas, enquanto 42,5\% consumiram algum tipo de droga ilícita (Tabela 2).

Dentre os consumidores de drogas, observou-se que a mais usada foi a maconha $(n=14,35 \%)$, sendo a droga de iniciação no submundo, seguida do crack $(n=12,30,1 \%)$, estando essa quase sempre associada a maconha, e cocaína ( $n=7,17,5 \%)$, dentre outras $(n=8,20 \%)$.

Quanto à terapia farmacológica implantada junto aos encarcerados para reduzir os danos neurológicos e/ou comportamentais causados pela droga destacam-se 0 antipsicótico Haloperidol $(n=40,100 \%)$ e o ansiolítico Diazepam 10mg ( $n=28,70 \%)$, estando todos os detentos em uso de dois ou mais medicamentos. Cumpre informar que, $41 \%$ dos usuários de drogas ilícitas, que praticaram homicídio, eram também portadores de algum distúrbio mental, capaz de influenciar no caráter violento de suas ações. Tais indivíduos apresentavam lesão cerebral em função de trauma ou doença que causou danos permanentes ou mesmo estados anormais de humor (CID 10 F) (Gráfico 1).

Considerando a tipificação do crime observou-se que todos cometeram o homicídio na modalidade qualificada, quanto ao motivo, pela futilidade conforme disposto no artigo $121 \S 2^{\circ}$ (inciso I) e torpeza (inciso II); ou quanto ao meio de execução, pela crueldade (artigo $121 \S 2^{\circ}$ inciso III) e traição (Artigo $121 \S 2^{\circ}$, inciso IV). O gráfico 2 demonstra a comparação entre a tipificação do crime e o consumo de drogas ilícitas.

\section{Discussão}

$O$ ato de matar alguém pode ser motivado por questões infinitamente variadas, praticada por pessoas, sendo estas do sexo masculino ou feminino. A vertente deste trabalho direcionou-se para uma instituição prisional masculina, por isso tem-se a totalidade de pessoas do sexo masculino e, ainda estudos comprovam que homens praticam, o homicídio, mais que as mulheres (25).

Observou-se também que os indivíduos com menor grau de instrução foram a maioria, consolidando os estudos epidemiológicos indicando que, os principais executores 
do crime são homens pobres com baixa ou nenhuma escolaridade e qualificação profissional (25).

A maconha é a droga ilícita mais usada mundialmente4, sua principal substância, tetra-hidrocanabinol (THC), causa vários efeitos farmacológicos que variam com a dose, a via de administração, a experiência do usuário, a vulnerabilidade aos efeitos psicoativos e o contexto do seu uso, produz alterações do humor, da percepção e da motivação, mas o efeito buscado pelos usuários é o "barato" (descrito como diferente do "barato" produzido por opióides ou estimulantes) (10).

Os efeitos em um fumante típico de maconha duram cerca de duas horas, durante este tempo, há comprometimento das funções cognitivas, da percepção, do tempo de reação, da aprendizagem e da memória, esta, principalmente de curto prazo (6). Embora não haja evidências convincentes de que a maconha pode provocar uma síndrome semelhante à esquizofrenia duradoura, existem numerosos relatos clínicos de que o uso da maconha pode precipitar recorrência em pessoas com história pregressa de esquizofrenia, (7) por outro lado estudos mais recentes revelam que a maconha piora quadros de esquizofrenia (12).

Em seguida ao uso da maconha destaca-se o crack, com elevada incidência de uso quando está relacionado aos homicídios, sendo uma droga feita a partir da mistura de cocaína com bicarbonato de sódio, geralmente fumada. É uma forma impura de cocaína e não um subproduto (3), portanto as conclusões a respeito da relação do crack, com a produção de comportamentos violentos é um campo em disputa na ciência (2).

Por conseguinte, observou-se, que a cocaína também faz parte do grupo de drogas ilícitas usadas na prática do homicídio sendo esta uma droga que como as demais, afeta os sistemas de neurotransmissão. Seu efeito agudo pode ser atribuído principalmente a um bloqueio da recaptação da dopamina (19), podendo também, envolver a participação de noradrenalina, serotonina, endorfinas, GABA (ácido gama-aminoburítico) e acetilcolina. As ações da cocaína nas vias dopaminérgicas são essenciais para a atividade reforçadora da droga. Com o efeito final na diminuição na quantidade de dopamina tem-se o aumento da atividade psicomotora, que induz comportamentos estereotipados e, diminui o consumo de alimentos (11).

Ressalta-se que, a exposição crônica à cocaína acarreta uma complexa deformação funcional do sistema nervoso devido à sobreposição de nodos do sistema nervoso 
hipersensibilizados à ação das monoaminas, que sofrem a alteração corriqueira à dessensibilização. Uma vez que existe a possibilidade, em princípio, de uma interação entre estruturas desse sistema dinamicamente deformado que perpetue algum componente dessa deformação, não se pode descartar a ideia de irreversibilidade de algum efeito crônico de certas drogas de abuso, entre elas a cocaína (19).

Diversas drogas usadas por eles, como heroína, muito consumidas no século XIX atuam sobre receptores específicos, e provocam um funcionamento mais brando do sistema nervoso e respiratório.(5) O LSD (acrônimo dietilamina ácido lisérgico) é capaz de provocar alterações na percepção, principalmente de caráter visual e auditivo, além de aceleração e desorganização do pensamento, com ideias soltas e perda do foco do pensamento. O humor torna-se lábil, podendo variar de situações de grande euforia a quadros de extremo mal-estar, marcados por tristeza e medo. Falhas na avaliação da realidade por vezes podem produzir sintomas paranóides (ideias de perseguição), usualmente momentâneos e restritos ao período da intoxicação (9).

O Êxtase é o nome popular dado à substância quimicamente conhecida como 3,4metilenodioximetanfetamina (MDMA)(9). Seus efeitos neuropsiquiátricos agudos incluem alterações na percepção do tempo e na percepção visual, com autoconfiança, empatia, diminuição da defesa e agressão seguida de aumento da interação social. Há relatos de aumento da energia emocional e física, atribuído a características psicoestimulantes da droga. Os efeitos em curto prazo são euforia, insônia, fadiga, humor deprimido e diminuição da ansiedade (26).

Atrelado a esses aspectos, foi possível observar que os indivíduos que já são portadores de doenças relacionadas ao Sistema Nervoso Central, diagnosticados com CID $10 \mathrm{~F}$, que é o código característico de acometimentos mentais, e apresentam seus sintomas neurológicos com o uso concomitante da droga, pioram o quadro de esquizofrenia, convulsão, delírios psicóticos, dentre outros (3).

Os medicamentos usados para tratar esses acometimentos do SNC (Sistema Nervoso Central), são também usados para tratar crises de abstinência e dependentes químicos. Os antipsicóticos são medicamentos inibidores das funções psicomotoras, a qual pode encontrar-se aumentada em estados, por exemplo, de excitação e de agitação, tendo a funçao farmacológica de bloquear os receptores dopaminérgicos (8) e estão sempre associados a um ansiolítico. 
Por sua vez, o ansiolítico promove a ligação do ácido y-aminobutírico (GABA), principal neurotransmissor inibidor, aos receptores na membrana dos neurônios. Com isso permitem um aumento de correntes iônicas através dos canais de cloreto, inibindo a atividade neuronal. Os benzodiazepínicos têm um efeito sedativo-hipnótico dependo da dose utilizada. Enquanto os antidepressivos inibem a recaptação da serotonina, fazendo com que haja uma diminuição na sensação de tristeza, desamparo, retraimento social e diminuindo o principal fator de risco, que seria o suicídio, que se encontra evidenciado nas crises de abstinência (11).

Todos os presidiários foram tipificados pelo menos em um dos incisos do artigo $121 \S$ 2ำ do Código Penal Brasileiro, onde no inciso I o indivíduo pratica o homicídio mediante paga ou promessa de recompensa, ou por motivo torpe e no inciso III, o indivíduo pratica o delito com emprego de veneno, fogo, explosivo, asfixia, tortura ou outro meio insidioso ou cruel, ou que possa resultar perigo comum (9). Houve uma diferença relevante entre os usuários e os não usuários, quando relacionado aos incisos I e III, porém não significante. Todavia, houve uma diferença significativa quanto aos presidiários que foram qualificados no inciso II, ou seja, homicídio praticado por motivo fútil segundo o Código Penal Brasileiro, e que fizeram uso de drogas ilícitas ao praticar o homicídio, fortalecendo a hipótese, que, a droga potencializa a violência.

\section{Conclusão}

Houve uma identificação do consumo de drogas ilícitas na potencialização da violência, diante da maior gravidade do homicídio praticado nestas condições.

O uso de medicamentos pelos detentos fez supor que se destinava em parte ao tratamento do dependente químico, buscando minimizar os efeitos da síndrome de abstinência, contudo, não foi possível descartar o seu emprego em face de uma doença mental ou psiquiátrica prévia.

Ao consumir algum tipo de droga ilícita o indivíduo, perde o controle emocional tendo diversos sintomas como alucinação, euforia, psicose, ilusões, sintomas de esquizofrenia, entre outros, que poderiam servir de motivação para a prática de delitos com requintes de crueldade.

É importante ressaltar também, que pessoas com menor grau de instrução e classe 
social menos favorecida, parecem estar mais expostas às drogas ilícitas e, às suas consequências.

\section{Referências}

1-Antunes G. Crack, mídia e periferia: uma representação social das "classes perigosas". Revista de Sociologia, 10 dez 2010, 1- 24.

2- Barata BB, Ribeiro MCSA. Desigualdades Sócias e homicídios da cidade de São Paulo 1998. Revista Brasileira de Epidemiologia, 2008, 11 (1):3-13. Disponível em http://dx.doi.org/10.1590/S1415-790X2008000100001. [Acesso em 7.agosto.2017]

3- Benetti SPC, GAMA C, Vitolo M, Silva, MB, D’Avila A, Zavaschi ML. Violência comunitária, exposição às drogas ilícitas e envolvimento com a lei na adolescência. Revista Brasileira de Psicologia. 2006 jun./dez; 37 (3): 279-286.

4- Bitencourt CR. Tratado de Direito Penal, Parte Especial: dos crimes contra a pessoa. 6 ed. São Paulo: Saraiva; 2007.

5- Cerqueira D, Lima RS, Bueno LI, Hanashiro O, Machado PHG, Lima AS. [Atlas]. Atlas da violência 2017. Rio de Janerio: Ipea; 2017.

6- Chaves FSR. Utilização do geoprocessamento no mapeamento criminal na região metropolitana de João Pessoa-PB. [Monografia]. João Pessoa: Universidade Federal da Paraíba; 2014.

7- Dayrrel, M. Drogas e vulnerabilidade à morte por homicídios: pesquisa em uma área urbana. [Dissertação]. Belo Horizonte: Programa de Pós-Graduação em Saúde Pública, Universidade Federal de Minas Geral; 2011.

8- Evangelista de Jesus D. Código penal Brasileiro. São Paulo: Saraiva; 1991.

9- Ferigolo M. Dietilamida de Ácido Lisergico. [Monografia]. São Paulo: Universidade de São Paulo; 2008.

10- Filho CCB, Assunção RM, Silva BFA, Marinho FC, Reis IA, Almeida MCM. Conglomerado de homicídios e tráficos de drogas, em Belo Horizonte, Minas Gerais, Brasil de 1995 a 1999. Caderno de Saúde Pública. Set./Out; 17(5):1163-1171.

11- Guimarães CF; Santos DVVD; Freitas RCD. Perfil do usuário de crack e fatores relacionados com a criminalidade em unidade de internação no hospital de psiquiatria de porto alegre (RS). Revista de Psiquiatria do Rio Grande do Sul. May. /Aug; 2008; 30 (2): 1 8. 
12- Laranjeira R, Ayer de Oliveira R, Roberto Cuce Nobre M, Marques Bernardo W, Usuários de substâncias psicoativas, abordagem, diagnóstico e tratamento. $2^{\underline{a}}$ ed. São Paulo: Sollo Comunicação; 2003.

13- Laranjeira R, Nicastri S, Pereira de Almeida O, Dractu L. Manual de Psiquiatria. Rio de Janeiro: Guanabara Koogan; 1996.

14- Minayo MCS. Violência e saúde. Rio de Janeiro: Fiocruz; 2006.

15- Ministério da Saúde. Produtos estratégicos para o SUS. Brasília, 2015. Disponível em: http://portalsaude.saude.gov.br/. [Acesso em 15.jul.2015].

16- Ministério da Saúde. Razão entre óbitos informados e estimado. Brasília. Disponível em: http://tabnet.datasus.gov.br/cgi/idb2012/matriz.htm. [ Acesso em 20.jul.2017].

17- Noronha EM. Direito penal. São Paulo: Atlas S.A; 1999.

18- Oliveira LG, Nappo SA. Crack na cidade de São Paulo: acessibilidade, estratégias de mercado e formas de uso. Archives of Clinical Psychiatry, 2008; 35(6):212-218.

19- Oriel M. O crack, efeitos da cocaína e efeitos farmacológicos do THC. Brasil, 2012. Disponível em: http://www.medcenter.com/Medscape/Default.html. [Acesso em 10.jul.2017].

20- Pedrozo MFM, Siqueira MEPB. Solventes de cola: abuso e feitos nocivos à saúde. Revista de Saúde Pública. 1989; 23(4):336-340. DOI: http://dx.doi.org/10.1590/S003489101989000400009

21- Ribeiro M, Marques ACPR, Laranjeira R, Alves HNPA, Araújo MR, Baltieri DA, et al. Abuso e dependência da maconha. Revista da Associação Médica Brasileira. Sept. /Oct 2005; 51(5):247-249.

22- Sanchez ZVDM, Nappo SA. Sequência de drogas consumidas por usuários de crack e fatores interferentes. Revista de Saúde Pública. 2002; 36(4): 420-430.

23- Silva MS. Homicídios e práticas da Justiça criminal em uma comarca do interior: Uberaba, MG, século XIX. In: Anais do Simpósio Nacional de História, ANPUH. Julho 2011. p. 1-14.

24- Sousa AVB. Contribuição da assistência farmacêutica na atenção primária à saúde no sistema prisional. [Monografia]. Fortaleza: Universidade de Fortaleza; 2011.

25- Sousa ER. Masculinidade e violência no Brasil: contribuições para reflexão no campo da saúde. Ciência \& Saúde Coletiva. Jan./Mar. 2005; 10 (1): 59-70.

26- Xavier CAC, Lobo PLD, Fonteles MMF, Vaconcelos SMM, Viana GSB, Sousa FCF. Êxtase (MDMA): efeitos farmacológicos e tóxicos. Revista de psiquiatria clínica. 2008; 35 (3): 2-25. 
Cadernos Ibero-Americanos

de Direito Sanitário

Cuadernos Iberomericanos

de Derecho Sanitario

27- Zanetti Junior O. Homicídios. Revista de Direito. 2010:1-15.

Recebido em: 4.9.2017

Aprovado em:23.9.2017

Como citar este artigo:

Lima CC, Lima RP, Nobre ACL. Uso de drogas ilícitas na prática do homicídio. Revista Cadernos IberoAmericanos de Direito Sanitário. 2017 jul./set, 6(3):118-128. 